\title{
Rede Urbana do Vale do Rio Pardo: o desenvolvimento e a influência das cidades
}

\author{
Débora Cristiele Kummer ${ }^{1}$ \\ Rogério Leandro Lima da Silveira ${ }^{2}$
}

\section{RESUMO}

Este artigo tem como objetivo observar e analisar, no período de 1990 a 2014, a importância e o papel das cidades médias e da rede urbana no desenvolvimento territorial, na escala da região do Vale do Rio Pardo (VRP). Este trabalho integra a pesquisa "Análise de Dinâmica e Transformações Recentes da Rede Urbana do Vale do Rio Pardo" que se vincula ao Programa de Pós-Graduação em Desenvolvimento Regional (PPGDR-UNISC), no âmbito do Observatório do Desenvolvimento Regional (OBSERVA-DR). A abordagem metodológica é qualitativa e envolveu inicialmente a revisão bibliográfica em relação aos conceitos de território, região, rede urbana e divisão territorial do trabalho, bem como sobre o processo de desenvolvimento urbano e regional do Vale do Rio Pardo-RS. Posteriormente, fez-se o levantamento, organização, e sistematização dos dados secundários referente a população e fluxos de capitais existentes entre as cidades da região. Com isso, apresentar-se-á como resultados o sistema viário multimodal, a população urbana e a taxa de urbanização, a população economicamente ativa por setor de atividade, a distribuição das agências e dos postos bancários e, por fim, a região de influência do Vale do Rio Pardo-RS.

Palavras-chave: Desenvolvimento Regional. Cidades Médias. Rede Urbana. Vale do Rio Pardo-RS.

\section{ABSTRACT}

This paper aims to observe and analyze, from 1990 to 2014, the importance and the role of medium and urban cities in territorial development in the scale of the Vale do Rio Pardo (VRP) region. This work integrates the research "Analysis of Dynamics and Recent Transformations of the Urban Network of the Vale do Rio Pardo", which is linked to the Regional Development Postgraduate Program (PPGDR-UNISC), within the scope of the Regional Development Observatory (OBSERVA-DR). The methodological approach is qualitative and involved initially the bibliographic review in relation to the concepts of territory, region, urban network and territorial division of labor, as well as on the urban and regional development process of the Vale do Rio Pardo- RS region. Subsequently, the survey, organization, and systematization of secondary data on population and capital flows among the cities of the region were carried out. Thus, the multimodal road system, the urban population and the urbanization rate, the economically active population by activity sector, the distribution of branches and banking stations, and, finally, the region of influence of the Vale do Rio Pardo-RS.

Keywords: Regional Development. Medium Cities. Urban Network. Vale do Rio Pardo-RS.

\footnotetext{
${ }^{1}$ Aluna do Curso de Arquitetura e Urbanismo da Universidade de Santa Cruz do Sul - UNISC.

${ }^{2}$ Professor do Departamento de História e Geografia, e do Programa de Pós-Graduação em Desenvolvimento Regional na Universidade de Santa Cruz do Sul. <rlls@unisc.br>
} 


\section{INTRODUÇÃO}

No processo de urbanização para Corrêa (1989, p.5) “a rede urbana passou a ser o meio através do qual produção, circulação e consumo se realizam efetivamente. Via rede urbana e a crescente rede de comunicações a ela vinculada, distantes regiões puderam ser articuladas, estabelecendo-se uma economia mundial”. Desse modo, tem-se por objetivo observar e analisar, no período de 1990 a 2014, a importância e o papel das cidades médias e da rede urbana no desenvolvimento territorial, na escala da região do Vale do Rio Pardo (VRP). O trabalho integra a pesquisa “Análise de Dinâmica e Transformações Recentes da Rede Urbana do Vale do Rio Pardo” realizada no Programa de Pós-Graduação em Desenvolvimento Regional (PPGDR-UNISC), no âmbito do Observatório do Desenvolvimento Regional (OBSERVA-DR), rede interinstitucional de pesquisa sobre o desenvolvimento regional.

A abordagem metodológica é qualitativa, e com a análise dos dados secundários coletados foi possível observar a consolidação do papel de comando da cidade média de Santa Cruz do Sul na rede urbana regional e a constituição da sua região de influência para além das cidades e áreas rurais do território do Vale do Rio Pardo, envolvendo também alguns centros locais da região do Vale do Taquari.

Destaca-se a importância desse estudo, uma vez que, é possível entender as articulações entre as diferentes cidades do Vale do Rio Pardo - RS e seu entorno, bem como, utilizar-se desses dados para uma melhor gestão governamental. Assim, compreender o papel da rede urbana no processo de desenvolvimento territorial, implica analisar como a rede urbana condiciona e reflete a divisão territorial do trabalho no território regional, bem como a mesma possibilita e desenvolve a dinâmica relacional entre centros urbanos de outros segmentos da rede urbana regional.

\section{FUNDAMENTAÇÃO TEÓRICA}

Os estudos sobre Rede Urbana não são recentes e desde o seu princípio se constituíram de fluxos materiais e imateriais, no entanto, com o aumento da globalização esses fluxos se intensificaram principalmente no que diz respeito aos fluxos imateriais. Cabe destacar que os fluxos materiais podem ser entendidos como objetos que possuem materialidade e volume, ou seja, estão de fato inseridos no espaço, como por exemplo, as infraestruturas e mercadorias. Já os fluxos imateriais se caracterizam pelos meios de 
comunicação e informação como internet, telefonia e fluxos de ideias.

As primeiras redes urbanas foram a rede de cidades greco-romanas, que perduraram até a Idade Média, e “as cidades portuárias [que] foram centros de urbanização por estabelecerem relações comerciais e de transporte. Com a Revolução industrial e a consolidação do capitalismo, aceleraram-se os processos que gerariam fluxos materiais e não materiais.” (CARNEIRO, et al. 2008, p. 25). A Globalização e a Terceira Revolução Industrial, mais especificamente, permitiram que essas redes se difundissem mundialmente com a formação das cidades globais ou megalópoles. Conforme Corrêa (1989, p.9):

O período que se estende de 1920 a 1955 caracteriza-se, entre outros aspectos, pelo aumento do interesse pelo estudo da rede urbana: algumas preposições teóricas e métodos operacionais são estabelecidos, e amplia-se o número de estudos empíricos. É deste período que aparecem, entre outras, as proposições de Christaller e de Mark Jefferson [...]. É a partir de 1955 que se verifica uma grande difusão dos estudos de redes urbanas [...] No Brasil é a partir de então que se iniciam os estudos sobre redes urbanas.

As Redes Urbanas, ou Redes de Cidades podem ser entendidas como uma articulação entre as cidades e os grandes centros urbanos que interagem entre si em escalas mundial, regional e local. Essa interação se dá de forma hierarquizada, ou seja, as cidades menores tendem a ser dependentes das cidades maiores.

Salienta-se que os estudos relacionados à rede urbana brasileira se constituem em “importante ferramenta de gestão governamental, econômica e social, pois possibilita um direcionamento mais acertado de investimentos urbanos” (FARIA, et. al., 2011, p. 55). Dentre os principais estudos realizados no Brasil com o intuito de hierarquizar a rede urbana brasileira o primeiro trabalho foi a Divisão do Brasil em Regiões Funcionais Urbanas, elaborado em 1966; o segundo, as Regiões de Influência das Cidades, elaborado em 1976; o terceiro em 1993, e por fim o quarto estudo realizado sobre as Regiões de Influência das Cidades em 2007 e publicado pelo IBGE em 2008, o qual dar-se-á ênfase neste trabalho. Em sua última edição as Regiões de Influência das Cidades apresentam alguns dos principais critérios utilizados para definir os centros da rede urbana brasileira.

[...] buscam-se informações de subordinação administrativa no setor público federal, para definir a gestão federal, e de localização das sedes e filiais de empresas, para estabelecer a gestão empresarial. A oferta de distintos equipamentos e serviços capazes de dotar uma cidade de centralidade - informações de ligações aéreas, de deslocamentos para internações hospitalares, das áreas de cobertura das emissoras de televisão, da oferta de ensino superior, da diversidade de atividades comerciais e de serviços, da oferta de serviços bancários, e da presença de domínios de Internet - complementa a identificação dos centros de gestão do território. (REGIC, 2008, p. 9) 
A integração da rede urbana de uma região é um indicativo do nível de desenvolvimento que essa apresenta, sendo que regiões mais dinâmicas economicamente tendem a ter uma melhor interligação com suas cidades, diferentemente de países subdesenvolvidos que apresentam pouca integração e uma organização territorial dispersa e pouca coesa. A rede urbana expressa também, a espacialização da divisão territorial do trabalho, em que cada cidade ou centro urbano exerce uma função complementar para todo o conjunto da rede, dessa forma um sistema de transporte articulado e um sistema de informações avançado permitem um melhor funcionamento operacional, por exemplo. Conforme Corrêa (1989, p. 6-7):

[Admite-se] a existência de uma rede urbana quando, ao menos, são satisfeitas as seguintes condições. Primeiro haver uma economia de mercado com uma produção que é negociada por outra que não é produzida local ou regionalmente [...]. Em segundo lugar verificar-se a existência de pontos fixos no território onde os negócios acima referidos são realizados, ainda que com certa periodicidade e não de modo contínuo. [...] A terceira condição refere-se ao fato da existência de um mínimo de articulação entre os núcleos anteriormente referidos, articulação que se verifica no âmbito da circulação, etapa necessária para que a produção exportada e importada realize-se plenamente, atingindo os mercados consumidores.

Em seu último estudo publicado em 2008, a pesquisa sobre as Regiões de Influência das Cidades - REGIC partiu do princípio que todas as cidades têm centralidade ao menos com relação à população rural do seu município, dessa forma de um total de 5.564 municípios do Brasil, na época, 4.625 foram identificados como centros locais.

\footnotetext{
As redes urbanas consolidam-se no território e refletem os desenvolvimentos econômicos, políticos e culturais de um dado período histórico que, com sua instabilidade e tensão, dinâmica e fluidez, causam impacto na configuração do território. A superposição de redes, por exemplo, cria uma distribuição desigual dos centros, reforçando, em alguns casos, o padrão concentrador, fazendo surgir centros especializados e até desconectando centros. (O’NEILL, 2010, p. 261)
}

Conforme O’Neill (2010) o estudo da rede urbana vem se mostrando cada vez mais importante, uma vez que, por meio desses pode-se ter um maior conhecimento e entendimento sobre as diferenças que se apresentam desde o nível local até o global, e com essas informações é possível auxiliar no direcionamento das políticas públicas visando propiciar maior homogeneidade no desenvolvimento das cidades. Conforme a REGIC (2008), “o avanço da divisão técnica e territorial do trabalho e as transformações decorrentes das novas formas de comunicação ampliaram a organização em redes - de produção e distribuição, de prestação de serviços, de gestão política e econômica - cujos nós são constituídos pelas 
cidades”. No entanto, se faz necessário um avanço homogêneo, de modo a proporcionar oportunidades de qualificação de mão de obra, acesso a informação, fontes de renda, oferta de produtos, entre outros a um maior número de pessoas e não somente a determinados centros.

Dessa forma, entende-se que haverá uma predominância de bens e serviços em determinadas cidades, no entanto, o que se coloca é a discrepância excessiva que implica em diferenças significativas na qualidade de vida de diferentes pessoas. Acredita-se que por meio dos estudos da rede urbana é possível ter um melhor planejamento da localização dos investimentos e da implantação de serviços (públicos e privados) em bases territoriais. Já que "as cidades constituem os locais onde se podem instalar mais racionalmente os serviços sociais básicos - de educação, de assistência à saúde, de administração pública e privada, serviços financeiros, serviços profissionais liberais, serviços culturais - destinados ao atendimento da população de toda uma região” (CONTE, 2014, p. 80).

\section{MATERIAIS E MÉTODOS}

Dentre os objetivos e ações da pesquisa a qual esse trabalho está vinculado está a observação e análise, no período de 1990 a 2014, da importância e do papel das cidades médias e da rede urbana no desenvolvimento territorial da região do Vale do Rio Pardo, no Sul do Brasil.

A abordagem metodológica é qualitativa e envolveu inicialmente a revisão bibliográfica em relação aos conceitos de território, região, rede urbana e divisão territorial do trabalho, bem como sobre o processo de desenvolvimento urbano e regional da região do Vale do Rio Pardo - RS. Posteriormente, fez-se o levantamento, organização, e sistematização dos dados secundários sobre a distribuição espacial da população e dos fluxos de capitais existentes entre as cidades da região, no período entre 1990 e 2014 resultando em uma série de tabelas, gráficos e cartogramas.

Isso com o objetivo de caracterizar a estrutura, a organização e a dinâmica de funcionamento da rede urbana do Vale do Rio Pardo identificando e analisando as principais tipologias, o conteúdo, a configuração espacial, as permanências e as transformações desses fluxos espaciais que animam a rede urbana regional. Portanto, compreender o papel da rede urbana no processo de desenvolvimento territorial, implica pesquisar como a rede urbana condiciona e reflete a divisão territorial do trabalho no território regional, bem como a mesma possibilita e desenvolve a dinâmica relacional com centros urbanos de outros segmentos da rede urbana nacional. 


\section{ANÁLISE DA REDE URBANA DO VALE DO RIO PARDO}

A rede urbana torna-se uma condição a partir do momento em que os processos de produção, distribuição, circulação e consumo são realizados e/ou articulados entre as cidades de uma rede (CONTE, 2014, p. 85). Essa articulação se dá juntamente com a evolução dos meios de transportes, comunicação e informação que permitem aumentar a intensidade da movimentação de pessoas, bens e serviços, capital, ideias, ordens, entre outros. Nesse contexto, o recorte da pesquisa se dá na região do Vale do Rio Pardo, situado no estado do Rio Grande do Sul, e que abrange 23 (vinte e três) municípios (Figura1). Esse conjunto de municípios ocupa uma área de 13.171,7 km² (2015) a qual possui 433.285 habitantes (2014), e apresenta uma densidade demográfica de 32,1 hab/km² (2013), segundo dados da Fundação de Economia e Estatística (FEE) - RS.

Na Figura 1 o qual foi elaborada a partir de dados fornecidos pelo Departamento Autônomo de Estradas de Rodagem (DAER - RS) 2015, é possível analisar as rodovias que fazem ligação entre os municípios do Vale do Rio Pardo, cabe destacar que as rodovias municipais não estão representadas, uma vez que, o objetivo é a análise das relações intermunicipais possibilitadas pelas principais rodovias da região.

Nesse sentido, destaca-se a importância da rodovia 471 que liga os municípios no sentido norte-sul, da rodovia 290 localizada nos municípios de Rio Pardo, Pantano Grande e em menor proporção Encruzilhada do Sul no sentido Leste-Oeste, e da rodovia 287 que faz a ligação dos municípios de Venâncio Aires, Passo do Sobrado, Santa Cruz do Sul, Vera Cruz, Vale do Sol e Candelária também no sentido Leste-Oeste. Salienta-se que esta é a única rodovia da região que possui postos de pedágio. Com relação às rodovias asfaltadas, notoriamente a parte central da região é mais privilegiada. Já na parte norte ainda há municípios sem acesso asfáltico e na parte sul, mais especificamente no município de Encruzilhada do Sul, devido a sua grande extensão também há problemas de acesso viário.

Nas margens do Rio Jacuí, dá-se destaque a estrada de ferro que foi inaugurada em 1883 em Rio Pardo, passando posteriormente pelos municípios de Vale Verde e General Câmara. Nos anos 90 deixaram de circular trens de passageiros, atualmente, os trens cargueiros fazem uso desta linha. Já com relação aos aeroportos há apenas um pavimentado localizado em Santa Cruz do Sul, e que recebe pequenas aeronaves, e outros quatro não pavimentados em Sobradinho, Venâncio Aires, Rio Pardo e Encruzilhada do Sul.

Essa inter-relação de acessos entre os munícipios, bem como a distribuição das rodovias na região se deve à diferentes fatores, porém, evidencia-se aqui a distribuição 
histórica da densidade populacional em cada município e a taxa de urbanização que esses apresentam, já que se entende a densidade populacional e a taxa de urbanização como fortes condicionantes para o desenvolvimento de um dado município.

Figura1: Vale do Rio Pardo: Sistema Viário Multimodal - 2015

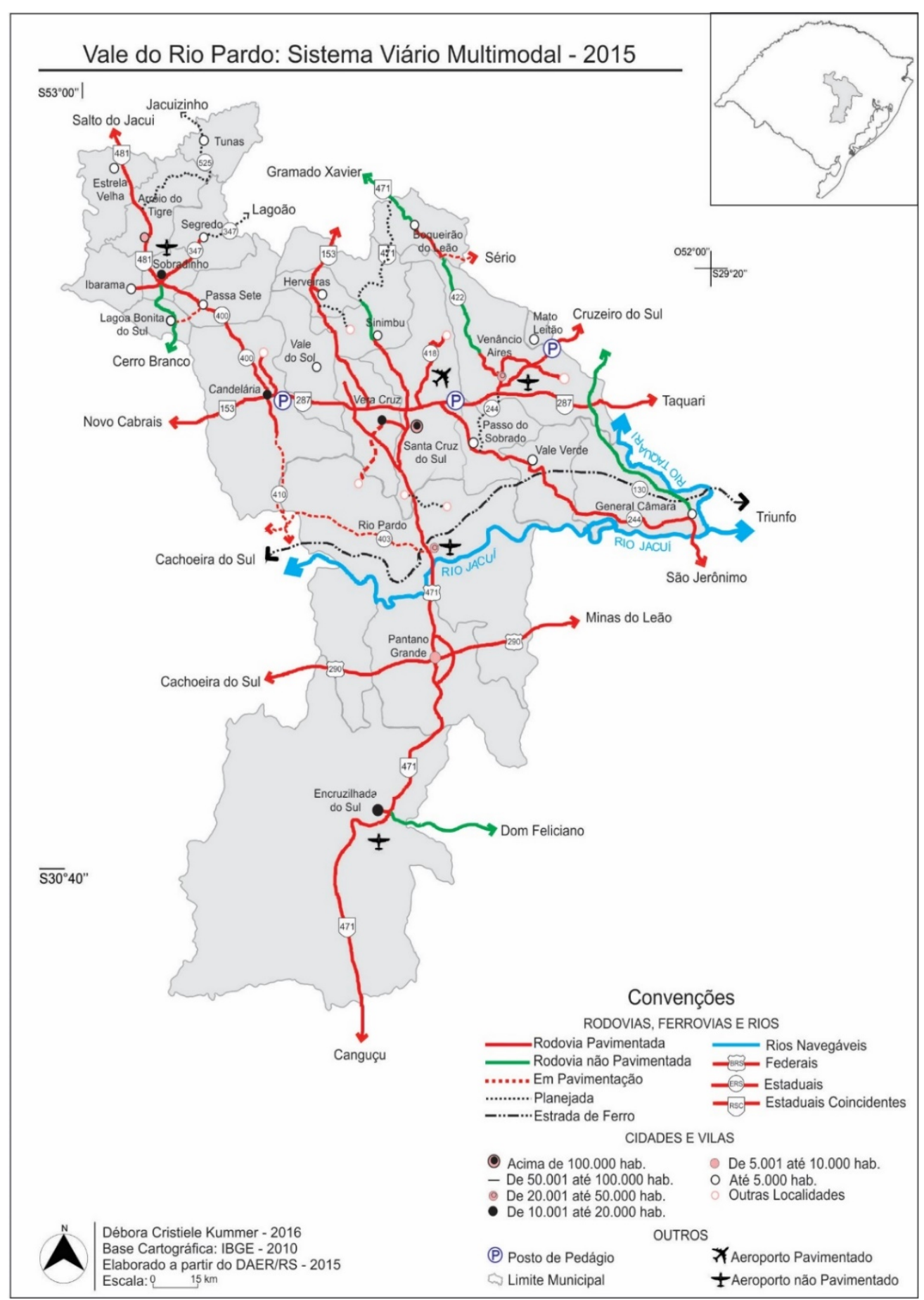

Fonte: Figura elaborada pela autora, com base nos dados do IBGE (2010) e DAER/RS (2015). 
A Tabela 1 permite a análise da população total, urbana e taxa de urbanização do Vale do Rio Pardo desde o ano de 1970 até o ano de 2010, pode-se ainda observar a relação de emancipações dos municípios ao longo dos anos. A análise da evolução da taxa de urbanização entre os municípios da região nesse período, revela o seguinte desempenho: para o ano de 1970 os municípios mais urbanizados são Santa Cruz do Sul (37,98\%), Rio Pardo (37,26\%), General Câmara (33,07\%) e Venâncio Aires (25,65\%), para 1980 permanecem os mesmos municípios com (55,34\%), (51,38\%), (34,97\%) e (34,46\%), respectivamente. No ano de 1991, tem-se Pantano Grande (79,79\%), Santa Cruz do Sul (67,03\%), Sobradinho (47,88\%) e Venâncio Aires (46,74\%) como os municípios mais urbanizados; para o ano de 2000 tem-se Santa Cruz do Sul (87,14\%), Pantano Grande (84,49\%), Sobradinho (71,47\%) e Rio Pardo (68,92\%). E por fim, em 2010, tem como municípios mais urbanizados Santa Cruz do Sul (88,86\%), Pantano Grande (84,02\%), Sobradinho (79,44\%) e Encruzilhada do Sul $(69,78 \%)$.

Percebe-se que ao longo destes anos preponderaram sete municípios como sendo mais urbanizados (Santa Cruz do Sul, Rio Pardo, General Câmara, Venâncio Aires, Pantano Grande, Sobradinho e Encruzilhada do Sul), enquanto que os demais municípios com exceção de Candelária que em 2010 possuía uma urbanização de (52,09\%) e Vera Cruz (55,54\%), são predominantemente rurais. Outros aspectos importantes a serem destacados são a taxa de urbanização do município de Sobradinho que cresceu mais intensificadamente no período de análise isso devido, principalmente, as emancipações que ocorrem na região norte fazendo com que o município perdesse área rural, diferentemente, o município de Santa Cruz do Sul, atualmente o mais urbanizado do Vale do Rio Pardo com 88,86\% que recebeu efetivamente um grande contingente populacional o qual se instalou na área urbana.

Nas Figuras 2 e 3, observa-se a disparidade populacional a qual a região apresenta, onde há uma concentração populacional urbana no centro-sul da região com destaque ao município de Santa Cruz do Sul que se constituí como um núcleo no Vale do Rio Pardo o qual possuía no ano de 2000, noventa e três mil setecentos e oitenta seis (93.786) habitantes na área urbana de um total de duzentos e trinta e sete mil setecentos e setenta e cinco (237.775) do Vale do Rio Pardo. Já no ano de 2010 houve um expressivo crescimento urbano na região sendo que esses números em Santa Cruz do Sul vão para cento e cinco mil cento e noventa (105.190) e o Vale do Rio Pardo chega a duzentos e sessenta e três mil novecentos e sessenta e dois habitantes (263.962) na área urbana. 
Figura 2: VRP: Distribuição da população urbana dos municípios por faixa de tamanho - 2000

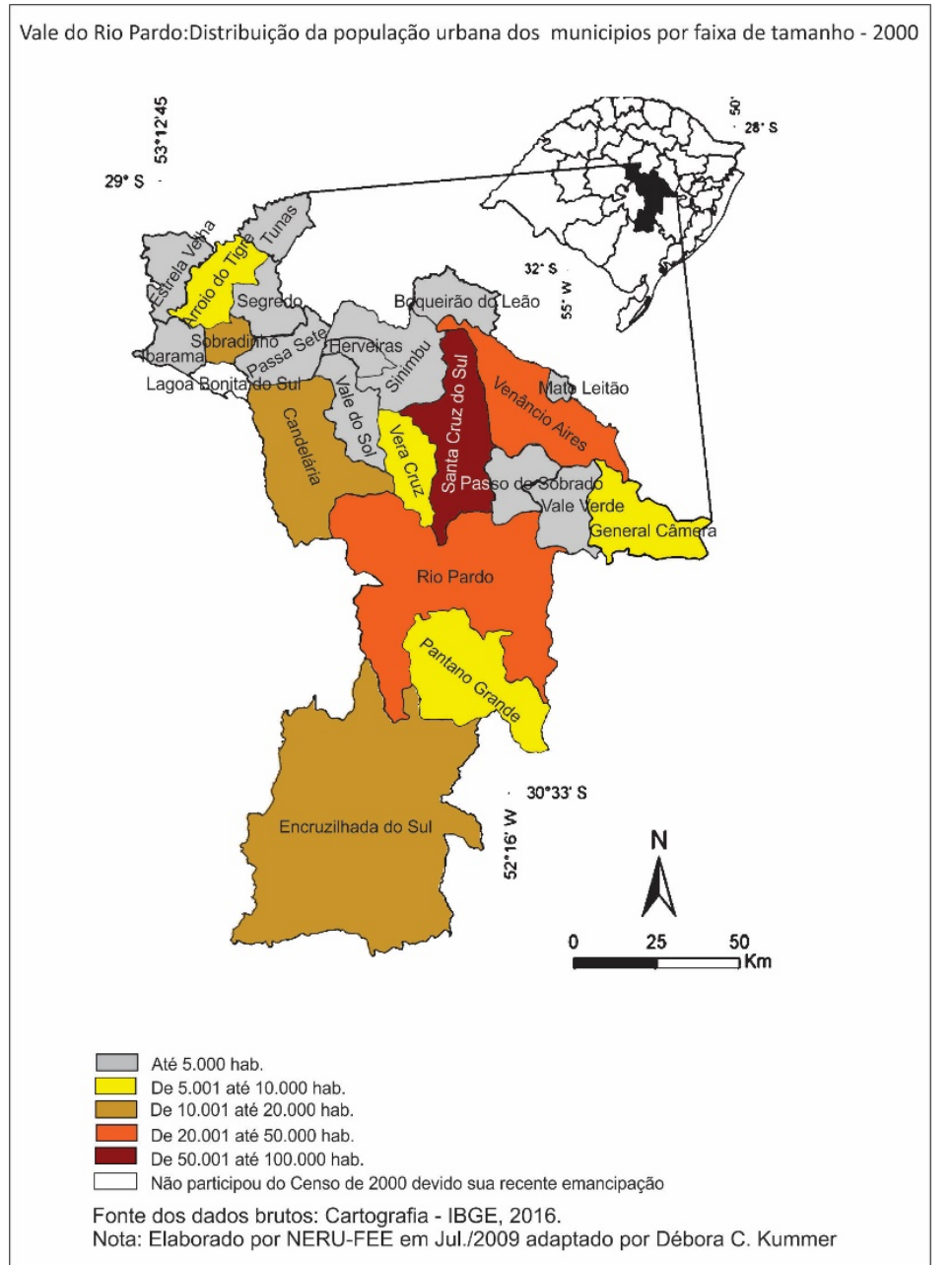

Fonte: Figura elaborada por NERU - FEE Jul./2009 adaptado pela autora, 2016.
Figura 3: VRP: Distribuição da população urbana dos municípios por faixa de tamanho - 2010

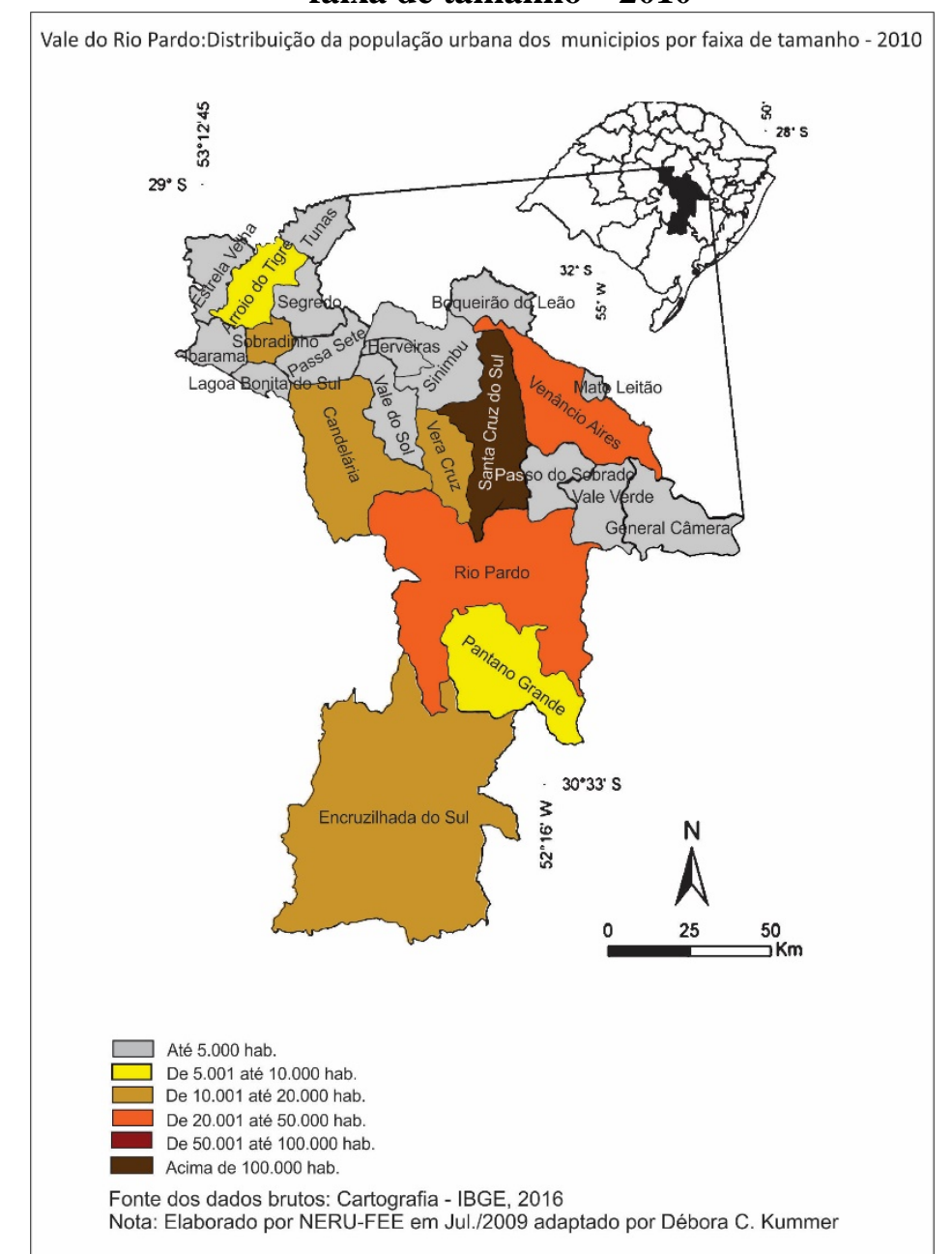

Fonte: Figura elaborada por NERU - FEE Jul./2009 adaptado pela autora, 2016. 
Outro aspecto importante é a população economicamente ativa (PEA), constituída por pessoas com 16 anos ou mais de idade. Observa-se nas tabelas 2 e 3 que no ano 2000, dentre os 22 munícipios da região, 16 (dezesseis) possuíam uma PEA predominantemente ocupada na agricultura, dentre os quais Herveiras, Passa Sete e Vale do Sol apresentavam mais de 80\% da população ocupada nesse setor. Os municípios que se destacam na prestação de serviço são 6 (seis): General Câmara, Pantano Grande, Rio Pardo, Santa Cruz do Sul, Sobradinho e Vera Cruz, já na indústria não havia nenhum município com predominância.

Já em 2010, dentre os 23 munícipios do Vale do Rio Pardo, 14 (quatorze) possuíam uma PEA predominantemente rural que eram: Arroio do Tigre, Boqueirão do Leão, Candelária, Estrela Velha, Herveiras, Ibarama, Lagoa Bonita do Sul, Passa Sete, Passo do Sobrado, Segredo, Sinimbu, Tunas, Vale do Sol e Vale Verde. Na prestação de serviço temse 8 (oito): Encruzilhada do Sul, General Câmara, Pantano Grande, Rio Pardo, Santa Cruz do Sul, Sobradinho, Venâncio Aires e Vera Cruz. E por fim, 1 (um) município com uma PEA predominantemente no setor industrial.

\section{Tabela 2: População Economicamente Ativa com 16 anos ou mais de Idade por Setor de Atividade e Total - Ano 2000}

\begin{tabular}{|c|c|c|c|c|c|c|c|c|}
\hline \multicolumn{9}{|c|}{ População Economicamente Ativa com 16 anos ou mais de Idade por Setor de Atividade e Total - Ano 2000} \\
\hline \multirow[t]{3}{*}{ Município } & \multicolumn{6}{|c|}{ Setor } & \multicolumn{2}{|c|}{ Total } \\
\hline & \multicolumn{2}{|c|}{ Agricultura } & \multicolumn{2}{|c|}{ Indústria } & \multicolumn{2}{|c|}{ Serviços } & \multirow[b]{2}{*}{ Absoluto } & \multirow[b]{2}{*}{$\%$} \\
\hline & Absoluto & $\%$ & Absoluto & $\%$ & Absoluto & $\%$ & & \\
\hline Arroio do Tigre & 4.366 & 62,5 & 916 & 13,1 & 1.706 & 24,4 & 6.988 & 3,4 \\
\hline Boqueirão do Leão & 3.099 & 73,7 & 255 & 6,1 & 847 & 26,7 & 4.201 & 2 \\
\hline Candelária & 8.816 & 56,9 & 2.540 & 16,3 & 4.133 & 26,7 & 15.489 & 7,6 \\
\hline Encruzilhada do Sul & 4.210 & 41,3 & 1.594 & 15,7 & 4.377 & 43 & 10.181 & 5 \\
\hline Estrela Velha & 1.673 & 79,4 & 104 & 4,9 & 330 & 15,7 & 2.107 & 1 \\
\hline General Câmara & 1.432 & 38 & 448 & 12 & 1.886 & 50 & 3.766 & 1,9 \\
\hline Herveiras & 1.393 & 84,3 & 37 & 2,2 & 221 & 13,4 & 1.653 & 0,8 \\
\hline Ibarama & 2.207 & 78,6 & 165 & 5,9 & 435 & 15,5 & 2.807 & 1,4 \\
\hline Lagoa Bonita do Sul & 0 & 0 & 0 & 0 & 0 & 0 & 0 & 0 \\
\hline Mato Leitão & 874 & 44,4 & 588 & 29,9 & 504 & 25,6 & 1.966 & 0,9 \\
\hline Pantano Grande & 1.099 & 23,2 & 1.150 & 24,3 & 2.479 & 52,5 & 4.728 & 2,2 \\
\hline Passa Sete & 2.509 & 89,9 & 58 & 2,1 & 225 & 8 & 2.792 & 1,3 \\
\hline Passo do Sobrado & 2.366 & 75,1 & 269 & 8,5 & 516 & 16,4 & 3.151 & 1,6 \\
\hline Rio Pardo & 5.634 & 33,9 & 2.999 & 18 & 7.985 & 48 & 16.618 & 8 \\
\hline Santa Cruz do Sul & 10.737 & 18,8 & 16.816 & 29,4 & 29.558 & 51,7 & 57.111 & 27,8 \\
\hline Segredo & 2.869 & 77,1 & 189 & 5 & 662 & 17,8 & 3.720 & 1,9 \\
\hline Sinimbu & 4.208 & 75,7 & 401 & 7,2 & 951 & 17,1 & 5.560 & 2,7 \\
\hline Sobradinho & 3.171 & 39,3 & 800 & 9,9 & 4.091 & 50,7 & 8.062 & 3,9 \\
\hline Tunas & 1.638 & 79,1 & 62 & 3 & 370 & 17,8 & 2.070 & 1 \\
\hline Vale do Sol & 5.491 & 86,8 & 178 & 2,8 & 655 & 10,4 & 6.324 & 3 \\
\hline Vale Verde & 1.074 & 68 & 142 & 9 & 364 & 23 & 1.580 & 0,7 \\
\hline Venâncio Aires & 13.492 & 39,7 & 10.271 & 30,3 & 10.158 & 29,9 & 33.921 & 16,6 \\
\hline Vera Cruz & 4.665 & 42,1 & 2.668 & 24,1 & 3.735 & 33,7 & 11.068 & 5,3 \\
\hline Vale do Rio Pardo & 87.023 & 42 & 46.650 & 22 & 76.188 & 37 & 205.863 & 100 \\
\hline
\end{tabular}

Fonte: Tabela elaborada pela autora, com base nos dados do IBGE (2000). 
Tabela3: População Economicamente Ativa com 16 anos ou mais de Idade por Setor de Atividade e Total - Ano 2010

\begin{tabular}{|c|c|c|c|c|c|c|c|c|}
\hline \multicolumn{9}{|c|}{ População Economicamente Ativa com 16 anos ou mais de Idade por Setor de Atividade e Total - Ano 2010} \\
\hline \multirow[t]{3}{*}{ Município } & \multicolumn{6}{|c|}{ Setor } & \multicolumn{2}{|c|}{ Total } \\
\hline & \multicolumn{2}{|c|}{ Agricultura } & \multicolumn{2}{|c|}{ Indústria } & \multicolumn{2}{|c|}{ Serviços } & & \\
\hline & Absoluto & $\%$ & Absoluto & $\%$ & Absoluto & $\%$ & Absoluto & $\%$ \\
\hline Arroio do Tigre & 5.059 & 61 & 910 & 11 & 2.329 & 28 & 8.298 & 3,7 \\
\hline Boqueirão do Leão & 3.316 & 69,4 & 304 & 6,3 & 1.158 & 24,3 & 4.778 & 2 \\
\hline Candelária & 9.580 & 54,7 & 2.822 & 16,1 & 5.099 & 29,2 & 17.501 & 7,6 \\
\hline Encruzilhada do Sul & 5.168 & 42,9 & 1.309 & 10,8 & 5.630 & 45,3 & 12.107 & 5,2 \\
\hline \begin{tabular}{|l|} 
Estrela Velha \\
\end{tabular} & 1.465 & 72,8 & 65 & 3,2 & 482 & 24 & 2.012 & 0,8 \\
\hline General Câmara & 1.527 & 40 & 403 & 10,5 & 1.888 & 49,5 & 3.818 & 1,7 \\
\hline Herveiras & 1.331 & 81,1 & 63 & 3,8 & 247 & 15,1 & 1.641 & 0,7 \\
\hline Ibarama & 2.160 & 81,5 & 66 & 2,5 & 424 & 16 & 2.650 & 1,1 \\
\hline Lagoa Bonita do Sul & 1.492 & 81,7 & 37 & 2 & 296 & 16,3 & 1.825 & 0,8 \\
\hline Mato Leitão & 787 & 33,5 & 845 & 35,7 & 727 & 30,8 & 2.359 & 1 \\
\hline Pantano Grande & 845 & 20 & 919 & 21,8 & 2.443 & 58,2 & 4.207 & 1,8 \\
\hline Passa Sete & 2.666 & 85,8 & 83 & 2,6 & 362 & 11,6 & 3.111 & 1,4 \\
\hline Passo do Sobrado & 2.583 & 65,4 & 493 & 12,5 & 867 & 22 & 3.943 & 1.7 \\
\hline Rio Pardo & 4.709 & 27,7 & 3.769 & 22,2 & 8.497 & 50,1 & 16.975 & 7,7 \\
\hline Santa Cruz do Sul & 9.205 & 13,6 & 18.383 & 27,3 & 39.817 & 59,1 & 67.405 & 28,9 \\
\hline Segredo & 3.104 & 78,3 & 185 & 4,7 & 674 & 17 & 3.963 & 1,7 \\
\hline Sinimbu & 4.710 & 75,1 & 590 & 9,4 & 969 & 15,5 & 6.269 & 2,8 \\
\hline Sobradinho & 2.135 & 26,2 & 1.510 & 18,5 & 4.478 & 55,3 & 8.123 & 3,6 \\
\hline Tunas & 1.948 & 76,1 & 63 & 2,4 & 547 & 21,5 & 2.558 & 1,1 \\
\hline Vale do Sol & 5.023 & 76,5 & 446 & 6,7 & 1.110 & 16,8 & 6.579 & 2,9 \\
\hline Vale Verde & 1.176 & 71,6 & 90 & 5,4 & 375 & 23 & 1.641 & 0,7 \\
\hline Venâncio Aires & 12.755 & 32,4 & 12.357 & 31,4 & 14.238 & 36,2 & 39.350 & 16,9 \\
\hline Vera Cruz & 4.323 & 31,1 & 4.060 & 29,2 & 5.515 & 39,7 & 13.898 & 5,9 \\
\hline Vale do Rio Pardo & 87.067 & 37 & 49.772 & 21,2 & 98.172 & 41,8 & 235.011 & 100 \\
\hline
\end{tabular}

Fonte: Tabela elaborada pela autora, com base nos dados do IBGE (2010).

Na Figura 4 pode se visualizar mais claramente a distribuição desses setores econômicos na região, sendo que o setor de prestação de serviços concentra-se, em especial, no centro. Ao Norte tem-se o município de Sobradinho que de certa forma se constitui como um núcleo da região norte. Ao Leste General Câmara, que por estar situado no limite da região estabelece conexões de mercado com as regiões Centro Sul, Metropolitano Delta do Jacuí e Vale do Taquari. E ao Sul tem-se Encruzilhada do Sul como um município com predominância na prestação de serviços. O setor da agricultura, o qual prevalece na região, está situado em especial, na região norte e ao leste com os municípios de Passo do Sobrado e Vale Verde.

As culturas agrícolas na região são variadas sendo divididas em lavouras permanentes e lavouras temporárias. Conforme dados do IBGE, 2010 as lavouras permanentes têm como principais cultivos banana, erva-mate, laranja e uva. E as lavouras temporárias cultivam arroz em casca, feijão em grão, fumo em folha, mandioca, milho em grão e soja em grão. Já com relação ao setor industrial, cabe destacar que esse possui apenas um município na região com predominância e que se destacou recentemente no censo de 2010, no entanto, apesar dessa predominância Mato Leitão é um município até então com uma distribuição uniforme entre os 
setores sendo 33,5\% na agricultura, 35,7\% na indústria e 30,8\% no setor de serviços.

Figura 4: VRP: População Economicamente Ativa com 16 anos ou mais de Idade por Setor de Atividade - 2010

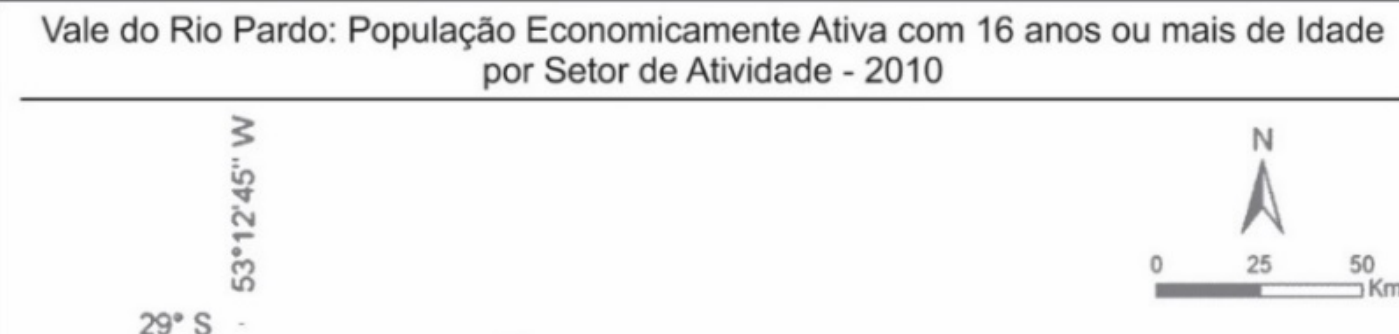

$29^{\circ} \mathrm{S}$

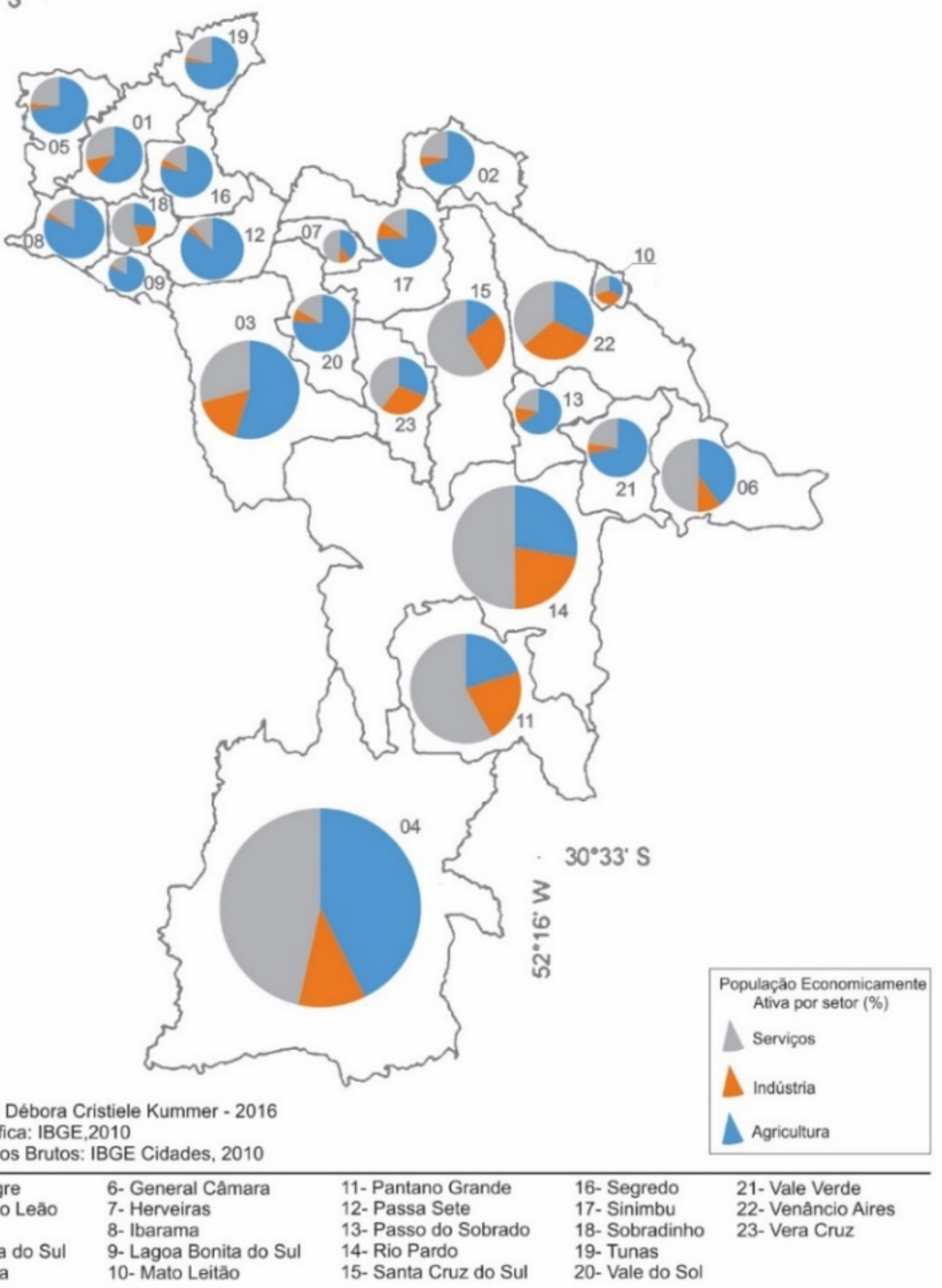

Fonte: Figura elaborada pela autora, com base nos dados do IBGE (2010). 
Em uma região é imprescindível ainda ter conhecimento sobre os fluxos de capitais, pois, a partir desses é possível identificar a distribuição do capital na região e onde há a maior concentração. Dessa forma, os fluxos de capitais podem ser analisados a partir da distribuição das agências e postos bancários bem como, o número de depósitos e operações de crédito.

Na Tabela 4 é possível analisar o número de agências bancárias em 2000, 2010 e 2014, e os postos bancários em 2014. Salienta-se que os municípios os quais não apresentam valores não possuem agências ou não foram informadas dentro do período de análise.

Tabela4: Distribuição das Agências e Postos Bancários no VRP

\begin{tabular}{|c|c|c|c|c|}
\hline \multirow{2}{*}{ Nome do Município } & \multicolumn{3}{|c|}{ Agências Bancárias } & \multirow{2}{*}{$\begin{array}{c}\text { Postos Bancários } \\
2014\end{array}$} \\
\hline & 2000 & 2010 & 2014 & \\
\hline Arroio do Tigre & 2 & 2 & 3 & 3 \\
\hline Boqueirão do Leão & & 1 & 2 & 1 \\
\hline Candelária & 4 & 4 & 4 & 4 \\
\hline Encruzilhada do Sul & 2 & 2 & 4 & 4 \\
\hline Estrela Velha & & 1 & 1 & 1 \\
\hline General Câmara & 2 & 2 & 2 & 1 \\
\hline Herveiras & & & & 1 \\
\hline Ibarama & & & 1 & \\
\hline \multicolumn{5}{|l|}{ Lagoa Bonita do Sul } \\
\hline Mato Leitão & & & & 3 \\
\hline Pantano Grande & 2 & 2 & 2 & 2 \\
\hline Passa Sete & & & 1 & \\
\hline Passo do Sobrado & & 1 & 2 & 1 \\
\hline Rio Pardo & 3 & 3 & 4 & 10 \\
\hline Santa Cruz do Sul & 12 & 17 & 16 & 64 \\
\hline Segredo & & 1 & 1 & \\
\hline Sinimbu & 2 & 2 & 2 & 1 \\
\hline Sobradinho & 3 & 3 & 4 & 3 \\
\hline Tunas & & & & 1 \\
\hline Vale do Sol & & & 2 & 1 \\
\hline Vale Verde & & & 1 & \\
\hline Venâncio Aires & 6 & 6 & 7 & 15 \\
\hline Vera Cruz & 3 & 3 & 4 & 4 \\
\hline Total VRP & 41 & 50 & 63 & 120 \\
\hline & & $\begin{array}{r}\text { Fonte do } \\
\text { Federação B }\end{array}$ & $\begin{array}{l}\text { Dados Bruto } \\
\text { sileira de B }\end{array}$ & $\begin{array}{l}\text { s: Cidades - IBGE, } 2016 \\
\text { ancos - Febraban, } 2016\end{array}$ \\
\hline
\end{tabular}

Fonte: Tabela elaborada pela autora, com base nos dados do IBGE (2016) e Febraban (2016).

Observa-se então, na Tabela 4 e nos gráficos 1 e 2, a centralidade das agências e postos bancários, bem como de depósitos e operações de crédito em Santa Cruz do Sul isso se deve tanto a densidade populacional quanto a população urbana do município, e não somente, cabe destacar as empresas fumageiras as quais são responsáveis pelo processamento do fumo produzido tanto na região do VRP como no sul do Brasil desencadeando um intenso fluxo de capital no município. Posterior a Santa Cruz do Sul, 
em menor proporção, porém, com maior número de agências, postos bancários, depósitos e operações de crédito tem-se Venâncio Aires, município o qual é o segundo maior da região e tem uma economia intensificada com a produção e exportação de erva-mate.

Gráfico 1: Vale do Rio Pardo: Número de Agências Bancárias por Município - 2014

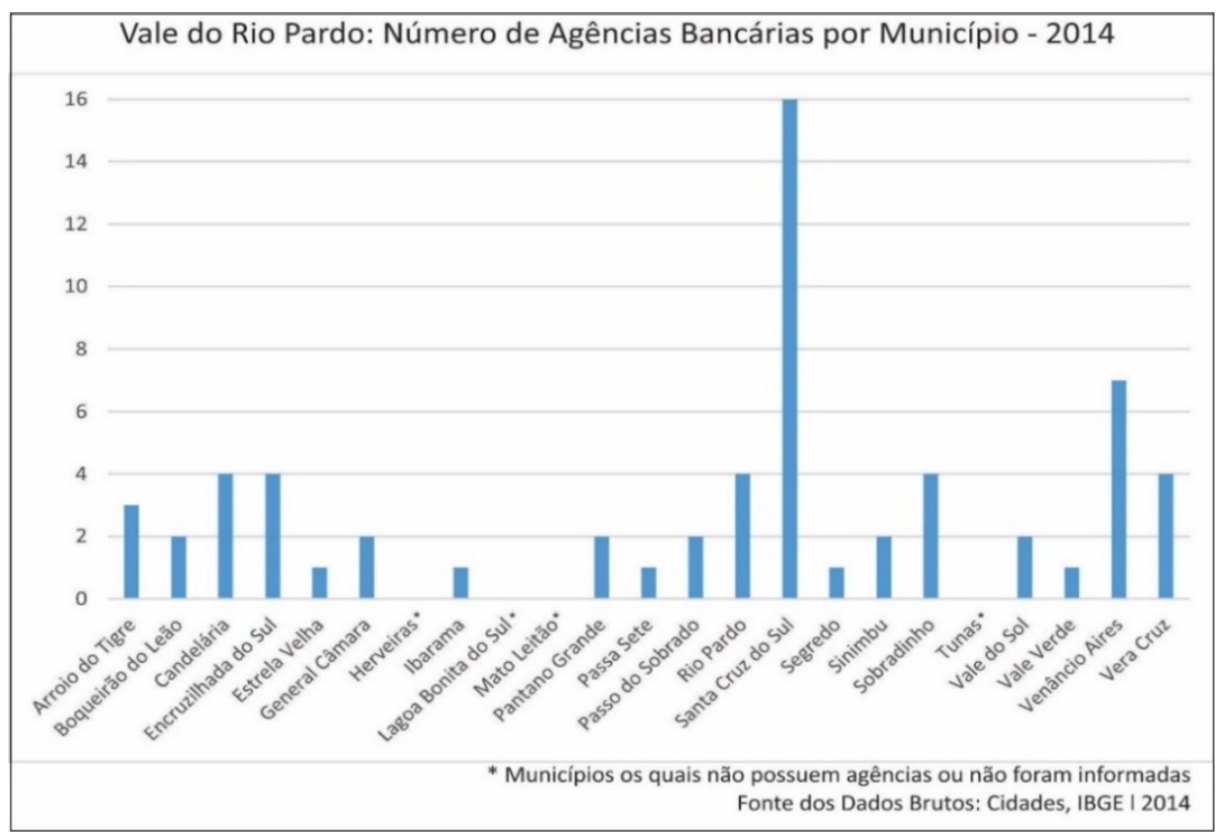

Fonte: Gráfico elaborado pela autora, com base nos dados do IBGE (2014).

Gráfico 2: Depósitos Bancários e Operações de Créditos no Vale do Rio Pardo - 2014

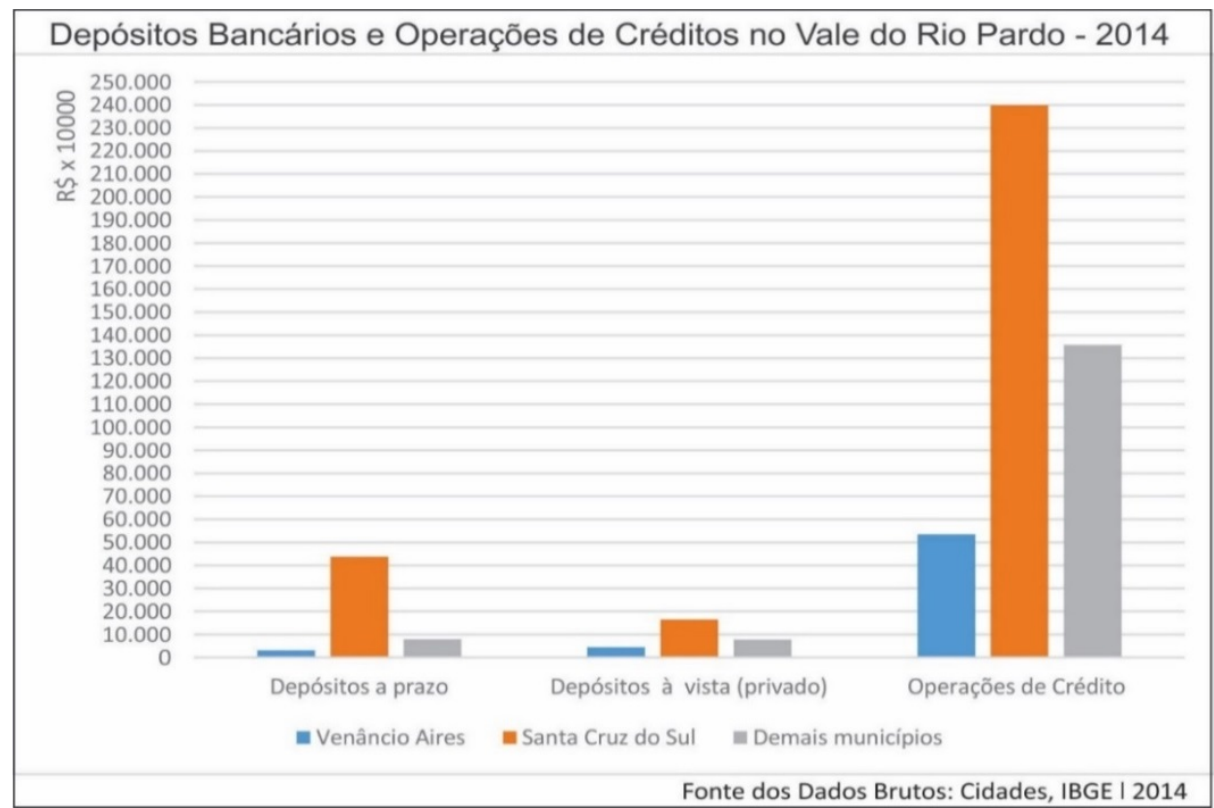

Fonte: Gráfico elaborado pela autora, com base nos dados do IBGE (2014).

Os demais municípios (com exceção de Encruzilhada do Sul, que no ano 2000 possuía duas agências e em 2014 foi para quatro), não sofreram grandes variações se mantendo ou 
aumentando apenas uma agência. Dessa forma, percebe-se a discrepância no fluxo financeiro presente na região onde mais da metade das movimentações financeiras acontecem somente no município de Santa Cruz do Sul.

Diante dos dados demonstrados no decorrer deste artigo, e de dados secundários coletados dos estudos dos Centros Urbanos e Regiões de Influência realizados por Regiões de Influência das Cidades - REGIC, 2008 pôde-se mapear a região de influência da metrópole Porto Alegre - RS sobre a região do Vale do Rio Pardo. Sendo assim, o mapa 5 demonstra a fragmentação que existe no Vale do Rio Pardo, isso se deve além de questões históricas, pela distância que se coloca entre os municípios.

Figura 5: Centros Urbanos e Região de influência dos municípios do VRP.

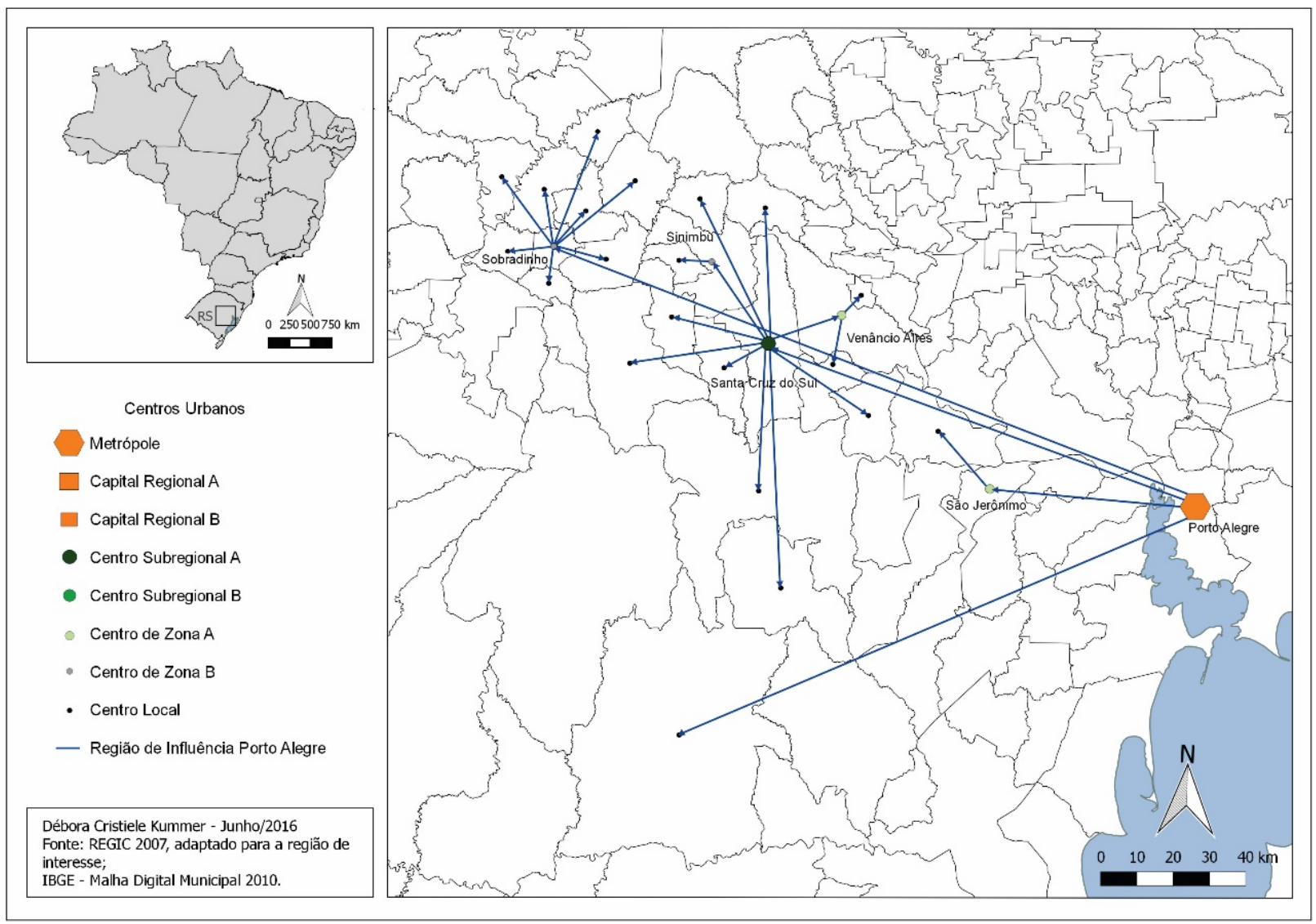

Fonte: Figura elaborada pela autora, com base nos dados do IBGE (2010) e REGIC (2007).

O Sul, por exemplo, constituído pelo município de Encruzilhada do Sul, devido a sua distância com o núcleo principal da região, ou seja, Santa Cruz do Sul, estabelece ligação direta com a metrópole Porto Alegre. General Câmara, situado ao leste da região sofre influência do município de São Jerônimo, o qual se localiza na região Centro Sul.

O município de Santa Cruz do Sul que se constitui no núcleo da região, possui influência sobre os municípios do Vale do Rio Pardo: Pantano Grande, Rio Pardo, Candelária, 
Vale do Sol, Vera Cruz, Sinimbu, Boqueirão do Leão, Venâncio Aires e Vale Verde e na região do Alto da Serra do Botucaraí, sobre o município de Gramado Xavier. Na região norte o município de Sobradinho se constitui como subnúcleo da região atendendo os municípios de Estrela Velha, Ibarama, Lagoa Bonita do Sul, Passa Sete, Segredo, Arroio do Tigre e Tunas no Vale do Rio Pardo e Lagoão na região do Alto da Serra do Botucaraí. Casos isolados se constituem na influência de Sinimbu sobre Herveiras e a influência de Venâncio Aires sobre Mato Leitão e Passo do Sobrado.

\section{CONCLUSÃO}

Por conseguinte, os estudos sobre rede urbana se constituem como um instrumento de planejamento, o qual pode direcionar os investimentos políticos de modo a priorizar as demandas regionais buscando um desenvolvimento homogêneo e com um maior índice de ligação dos municípios da região. Assim, os resultados da pesquisa permitem observar que o Vale do Rio Pardo possui fragmentações e diferentes formas de desenvolvimento.

O índice de ligação dos municípios se dá basicamente de forma hierarquizada no Norte com o município de Sobradinho o qual possui maior infraestrutura na prestação de serviços e no centro da região com Santa Cruz do Sul que possui uma área de influência mais ampla do que Sobradinho devido a concentração industrial, em especial, das fumageiras e também das universidades presentes no município. A influência de Santa Cruz do Sul se expande além das fronteiras do Vale do Rio Pardo ou até mesmo do Rio Grande do Sul, quando se trata das industrias de fumicultura a abrangência de Santa Cruz do Sul se estende até Santa Catarina e Paraná.

O Vale do Rio Pardo caracteriza-se como uma região predominantemente agrícola, com vastas áreas rurais e municípios com uma densidade demográfica reduzida, nesse contexto destaca-se Santa Cruz do Sul com características de cidade média devido ao seu contingente populacional e oferta de bens e serviços. Santa Cruz do Sul, então, é entendido como um polo da região, uma vez que, possui infraestrutura e serviços que só estão instaladas nessa cidade e atendem toda região. Já Sobradinho é um núcleo localizado na região norte que também possui oferta de bens e serviços os quais não estão presentes nos demais municípios do seu entorno.

Sendo assim, o entendimento de como se constitui a região, seu desenvolvimento, suas deficiências e potencialidades, é necessário para que haja o desenvolvimento de uma região menos desigual no seu conjunto. Principalmente, atualmente, em que a globalização da economia tem-se caracterizado pela promoção de intensos e complexos fluxos de capitais, 
conhecimento, pessoas e mercadorias resultando em crescentes incertezas quanto ao desenvolvimento dos territórios tanto regionais como nas demais escalas espaciais.

\section{REFERÊNCIAS}

CARNEIRO, R. B. et al. Discussão teórica sobre o conceito de rede urbana. Geografia's, Feira de Santana, n. 1, p. 25 - 29, maio/nov. 2008. Disponível em: <http://www2.uefs.br/maisgeografias/ARTIGO4_07.pdf >. Acesso em: 10 jan. 2017.

CONTE, C. H. Rede urbana: uma breve abordagem teórica. GeoAtos, Departamento de Geografia da FCT/UNESP, Presidente Prudente, v.1, n. 14, p. 76-93, jan./ jun. 2014. Disponível em: $<$ http://revista.fct.unesp.br/index.php/geografiaematos/article/viewFile/2625/pdftmf $>$. Acesso em: 22 fev. 2017.

CORRÊA, R. L. A Rede Urbana. São Paulo. Editora Ática, 1989.

Departamento Autônomo de Estradas de Rodagem (DAER-RS). Disponível em: <http://www.daer.rs.gov.br/inicial >. Acesso em: 27 mai. 2016.

FARIA, R. S. de. et al. Estudos recentes sobre a rede urbana brasileira. Revista Brasileira de Estudos Urbanos e Regionais.v.13, n. 2, p. 55 - 70, nov. 2011. Disponível em: <http://repositorio.unb.br/bitstream/10482/12184/1/ARTIGO_EstudosRecentesSobre.pdf>. Acesso em: 16 jan. 2017.

Federação Brasileira de Bancos (Febraban). Disponível em: <https://portal.febraban.org.br/ > . Acesso em: 22 de abr. 2016.

Fundação de Economia e Estatística (FEE)._Disponível em: <http://www.fee.rs.gov.br/>. Acesso em: 03 mar. 2016.

Instituto Brasileiro de Estatística e Geografia - Cidades (IBGE-Cidades). Disponível em: <http://www.cidades.ibge.gov.br/>. Acesso em: 22 mar. 2016.

IBGE, Regiões de Influência das Cidades. Rio de Janeiro: Ministério do Planejamento, Orçamento e Gestão, 2008. 2 Disponível em: <http://www.mma.gov.br/estruturas/PZEE/_arquivos/regic_28.pdf>. Acesso em: 10 abr. 2016.

O’NEILL, M. M. Rede urbana. Atlas Nacional do Brasil, Redes Geográficas. p. 261 - 272, $2010 . \quad$ Disponível em: $<$ http://biblioteca.ibge.gov.br/visualizacao/livros/liv47603_cap6_pt1.pdf >. Acesso em: 13 dez. 2016. 